\title{
Research on Methods of Fine Arts Teaching in Primary Schools of Minority Areas and Its Countermeasures*
}

\author{
Weiwei Chen \\ Central Primary School of Qingyuan Town \\ Yizhou, China 546300
}

\begin{abstract}
Literature review method and logical analysis method are used to discuss methods of fine arts teaching in primary schools of minority areas under new curriculum reform. The results indicate: Methods and countermeasures include: update teaching idea, improve teachers' professional level of fine arts, develop and utilize curriculum resources, train students' comprehensive ability, develop their interest and attach importance to teaching process and methods.
\end{abstract}

Keywords-new curriculum reform; minority areas; fine arts teaching; methods and countermeasures

\section{INTRODUCTION}

With continuous development of society, people realize fine arts are closely linked to our life. Fine arts education can promote overall quality of people. What kind of fine arts education can adapt to social development? How to provide high quality fine arts education for our society? These problems must be solved by fine arts educators, administrators even the whole society. The proposition and implementation of new curriculum standard accelerates the reform of art curriculum and effectively improves the position of art curriculum, promotes the reform and development of fine arts education as well as triggers overall and profound reform of in. Under the background of new curriculum reform, ways of fine arts teaching in primary schools of minority areas include: update teaching idea, improve teachers' professional level of fine arts, develop and utilize curriculum resources, train students' comprehensive ability, develop their interest and attach importance to teaching process and methods.

\section{UPDATE IDEA OF FINE ARTS TEACHING IN PRIMARY SCHOOL OF MINORITY AREAS}

The transformation of teaching idea means teachers guide students to learn actively instead of dominating. Like teaching of other subjects, in traditional fine arts teaching, teachers teach and seldom consider how to stimulate students' creativity but let students learn passively. Students receive the painting technique and skills with repeated fixed model, so they paint works with sameness. However, if teachers let students feel objects and image, they will

*Fund project: 2017 western fund project of National Social Science Fund, project number: 17XTY001 produce diversified works because they have different ways of thinking. [1] Therefore, good learning environment is indispensable for primary and middle school students. Teachers must care for and encourage them and expand space for their imagination. Paintings of primary and secondary school students integrate with their living environment. Although "scrawl" only lasts for a short period, it furthest reflects students' instinct and personality. Nowadays, fine arts education in middle and primary schools must let them have explicit knowledge of fine arts and let parents even the society coordinate with schools to create "artistic environment". School and fine arts teachers should communicate with class teachers or parents, in order to understand students' characteristics and psychological status and reasonably choose teaching means, as well as teach students in accordance with their aptitude and promote classroom teaching.

\section{IMPROVE PROFESSIONAL LEVEL OF FINE ARTS TEACHERS IN PRIMARY SCHOOLS}

With the development of fine arts education in primary schools, theoretical and practical problems must be solved, such as the relation between the construction of a harmonious society and the development of fine arts education, the relation between popularization and improvement in fine arts education in middle and primary schools. Therefore, scientific research must play a leading role in fine arts education. First, refer to beneficial experience of fine arts education in various countries in the world and all cultural heritages; [2] second, roundly absorb research results in humanities, social science and natural science, pay special attention to invention and application of high-tech achievements; third, actively bring talents of theoretical research of other disciplines in scientific research of fine arts and learn from them, in order to improve the theoretical quality and scientific research ability. Teachers must improve artistic quality to develop artistic connotation of different disciplines. [3] Meanwhile, they have to constantly improve professional skills and update knowledge structure to meet demands of teaching development. 


\section{DEVElOP AND UTILIZE LOCAL CURRICUlum RESOURCES}

New curriculum reform emphasizes "the development and utilization of curriculum resources". It requires teachers to review the existing teaching resources and find "environment" for teaching and teaching resources in it. Fine arts education is "humanistic" education to train humanistic spirit, "paying attention to the value of 'people' and the survival existence of "people"". They should realize the influence of social environment and regional cultural resources under "broad environment" on fine arts teaching. Shaping and training humanistic spirit is inseparable from national culture and tradition, which are source of fine arts education and teaching resources. We should excavate, integrate and use reasonably. Instead of "copying" local resources, teachers must discard the dross and select the essential, creatively select and scientifically set and reasonably allocate curriculum resources, in order to inherit and update local regional culture and human cultural heritage and construct basic curriculum of fine arts education. [4] Students have opportunities to contact rich artistic information, know about art, history and culture of China even the whole world, feel characteristics, expand artistic version as well as identify national culture. We should furthest broaden students' horizon and stimulate students' enthusiasm in participating in and understanding art and national customs, national art and cultural background, the unique expression way and the diverse culture, in order to let them form artistic accomplishment and ability. [5] Therefore, fine arts teachers can be organized to do subject study and attend training to change their narrow attitudes toward curriculum resources of fine arts. At the meantime, teachers can learn to actively and pertinently explore local resources to strengthen the application of local cultural resources. [6] Fine arts teachers are required to flexibly use local cultural resources of fine arts.

\section{TRAIN COMPREHENSIVE QUALITY OF PRIMARY SCHOOL STUDENTS}

\section{A. Fully Train Students' Perception in Fine Arts Teaching}

It is well known that painting is the main part of fine arts teaching. It closely relates to the training of students' perception. The understanding and appreciation of painting comes from the perception of painting object. There are numerous teaching forms of painting, which have different demands for students' perception and observation ability, such as sketching and copying. Students should observe roundly instead of concentrating on details, and determine proportional relation, structural relation, light and shade relations, space, perspective relation, relation of blankness and actuality, and relation of the strong and the weak between objects. They can more accurately describe objects after observing roundly. Correct observation method has a formula: integrity to locality to integrity. Moreover, teachers must guide students to consider size of painting according to material objects and make reasonable arrangement in direction, height and density.

\section{B. Fully Train Students' Observation Ability in Fine Arts Teaching and Improve Their Insight in Life}

Teachers must guide students to directly observe and understand objects. Matisse, the representative of modernist school observes, "Creativity comes from observation, which is creative activity and needs efforts". Observation can train students correct observation methods and good observation habit and memory and then promote their intellectual development. For example, teachers can ask students to remember objects of observation first, and portray people around them through methods of summary and observation, find the beauty of personality and reflect people's inner world. Students can acquire expressional language of beauty from visual sense through aesthetic principle and means of artistic analysis, and obtain sense of satisfaction in success. [7]

\section{Train Students' Innovation Consciousness and Form Characteristic Innovation Spirit}

It proposes in new Curriculum Standards of Fine Arts that "Building creativity in the 21 st century has become the basic orientation of contemporary fine arts curriculum". Folk fine arts are folk arts, and the working masses are the most creative artistic creators, so folk fine arts are one of the best ways to train students' creativity and innovation spirit. Art comes from life and exceeds life. Tremendous artists at all times and in all over the world absorb nourishment from folk fine arts and seek artistic innovation. Utensils in daily life, articles for folk activities and works of folk fine arts for cultural inheritance organically combine function and aesthetics, furthest realize social function and provide source for pure artistic creation. The cultivation of creativity and innovation spirit cannot do without the development of abstract thinking and imagery thinking. Integrating the development of imaginary thinking with folk fine arts will develop imaginary thinking of primary school students. [8]

\section{AROUSE STUDENTS' INTERESTS IN FINE ARTS}

Interest is the best teacher. In new curriculum reform, teachers are required to emancipate their minds and serve as organizer and participant of students' learning, let students actively observe things. Therefore, teachers should carry out humanistic teaching and realize "lead-in with interests", interaction, positive evaluation and image guidance and popularize "pleasant teaching".

\section{A. Create Conditions}

Primary school students are fickle in affection. Teachers should create pleasant situation and use flexible methods to arouse students' curiosity and learning interests as well as expand their imagination. For example, they can cit poetry with philosophy, and quotes by famous people and fascinating stories to close the gap between students and real life, combine students' cognition with emotions.

\section{B. Communicate Actively}

Students want to be attention-getting and show talent and intelligence. Therefore, in classroom teaching, teachers can popularize interaction of "question and answer mode", provide more opportunities for students to develop ability, 
allow them to freely choose objects to depict and advocate the participation of all to improve students' learning initiative.

\section{Amend Teaching Evaluation Standards}

In fine arts teaching in primary school, teachers should be "moderate" on expectation of students, neither teaching to develop all students into talents nor indulging them. Qualityoriented education emphasizes personality development, and students have obviously different personality and temperament as well as comprehensive ability. Therefore, teachers should formulate different evaluation standards and develop students' potential. Classroom is important for communication between teachers and students. Teachers must evaluate timely in class, praise more and criticize less to stimulate students' learning enthusiasm and help "underachiever" to establish learning confidence.

\section{Personalize Teaching Language}

Different from other disciplines, fine arts education gives us aesthetic perception. Personalized language should be scientific and vivid with philosophy. Fine arts teachers must constantly improve their artistic culture and cultural taste, absorb nourishment from literature and music and try hard to realize "enchanting, humorous and passionate" teaching. Furthermore, personalized language contains teachers' beautiful behavior and achievements. [9] The establishment of teachers' image and prestige depends on their professional ability.

\section{E. Organically Combine Classroom Teaching of Fine Arts with Extracurricular Activities to Arouse Learning Interests}

Aesthetic education on students is mainly carried out through fine arts teaching in class. Extracurricular fine arts teaching is beneficiary supplement and improvement of fine arts teaching in class. According to students' interests and conditions, schools can organize students to learn watercolor, paper cuttings, sketch and seal cutting, or invite some experts to guide; organize students to visit fine arts exhibition; show excellent fine arts works to students through video, network and projection; organize relevant knowledge lecture and let students participate in practical activities on and off campus, such as write wall newspaper, regularly hold gallery, in order to let students see their talent of fine arts creation and arouse their learning interests.

\section{REFORM TEACHING PROCESS AND METHODS}

\section{A. Attentions Must Be Paid to Teaching Design}

New educational concept aims at training people's aesthetic standard, aesthetic judgment, creative ability and aesthetic taste. Teachers must use flexible teaching means and elaborately arrange teaching contents with original conception to arouse students' learning interests in depicting beautiful things and the impulse to create. [10] At the meantime, contents that train students' knowledge transfer and divergent thinking must be selected. Except for the fine arts learning in traditional sense, teachers must consider whether it avails the development of students' integrated quality and creative ability and the improvement of students' personality. They should guide students to break through the traditional thinking habit and consciously operate roundly, in order to train students' divergent thinking ability.

\section{B. Integrate Teaching with Learning to Promote Teaching Development}

In teaching, teachers and students realize mutual promotion and joint development, especially in fine arts teaching. In contemporary fine arts education, students' dominant position is further strengthened. As guide of teaching activities, fine arts teachers must have good professional quality and teaching ability. Sukhomlinskii, the famous educator of the Soviet Union, observes: Teachers must be adept in reading and thoroughly understand the discipline and textbook and appeal to students in class; have professional psychological knowledge and grasp methods to research children; have good language accomplishment. It makes teachers have better performance in choosing teaching contents, designing teaching scheme, using teaching methods, and teaching and scientific research as well as student management, in order to meet students' development needs. [11]

\section{Pay Attention to Social Development and Improve Teaching Level through Varied Teaching Means}

In the contemporary era, the discipline of fine arts is more "practical" with prominent humanistic characteristics, including painting, calligraphy, handwork, process design, appreciation, folk art, architecture, sculpture and science and technology. Therefore, in order to meet demands of contemporary society for fine arts education, except for directly teaching professional knowledge, teachers must carry out practical teaching and expand fine arts teaching and manifest characteristics of contemporary fine arts education. Except for traditional teaching aids like model painting, game and story, they must flexibly use diversified teaching methods such as computer, network, video, music, visiting, exploration and discussion; exchange with students to develop their imagination and creative ability; make the best of local resources of fine arts teaching according to local conditions, etc. They are effective to arouse students' learning interest and improve teaching level.

\section{REFERENCES}

[1] Hou Wenyong. Thinking on the Implementation of New Curriculum Objective in Fine Arts Teaching of Middle and Primary Schools [J], Journal of Teaching and Management, 2011,(9):85-86

[2] Huang Zhihua. Exploration on Reform of Fine Arts Education in Middle and Primary Schools of Remote Mountain Area [J], Journal of Teaching and Management, 2009,(2):112-113

[3] Jin Changhao, Ye Xiaomin. Investigation on Development Status of Fine Arts Education in Middle School of Cenxi City [J], Grand Stage, 2013,(4):195-196

[4] Luo Xiaofei. Localization and Innovation-Research on Fine Arts Education with Regional Culture as Educational Resource [J], Journal of Teaching and Management, 2012, (10):142-143

[5] Yan Shuqin. Application of Local Cultural Resources to Fine Arts Teaching in Middle and Primary Schools of Nantong [J], Education Review, 2012,(1):96-98

[6] Gao Diankai, Wu Amei. Function of Folk Fine Arts in Fine Arts Education in Middle and Primary Schools in Rural Areas [J], Journal 
of Shanxi Normal University (Social Science Edition), 2009,35(2):196-198

[7] Jian Bo. Thinking on Development of Basic Fine Arts Education [J], Education Exploration, 2006, (7):66

[8] Li Rui. Exploration on Strategies for Fine Arts Teaching in Middle and Primary Schools [J], Journal of Teaching and Management, 2012, (1):131-132

[9] Tian Hao. Ways to Realize Scientific Fine Arts Teaching in Middle and Primary Schools [J], Journal of Teaching and Management, 2010, (10): $157-158$

[10] Wang Shengxuan. Exploration on Functions of Folk Fine Arts in Fine Arts Education in Primary Schools [J], Journal of Teaching and Management, 2014,(7):116-119

[11] Li Hua, Ping Jun. Research on Innovative Strategy in Fine Arts Education [J], Journal of Teaching and Management, 2016, (1)90-91. 